\title{
Exposição de fibroblastos da cápsula de Tenon normal de portadores de pterígio ao 5-fluorouracil e à mitomicina $\mathrm{C}$
}

\author{
Exposure of normal Tenon's capsule fibroblasts from pterygium to 5-fluorouracil and \\ mitomycin $C$
}

\author{
Magda Massae Hata Viveiros ${ }^{1}$ \\ Silvana Artioli Schellini ${ }^{2}$ \\ João Candeias ${ }^{3}$ \\ Carlos Roberto Padovani ${ }^{4}$
}

\begin{tabular}{|l|}
\hline RESUMO \\
\hline Objetivo: Avaliar a atividade proliferativa dos fibroblastos da cápsula de \\
Tenon normal, proveniente de portadores de pterígios primários e reci- \\
divados. Métodos: Foi realizado estudo prospectivo, aleatório, avalian- \\
do-se fragmentos da cápsula de Tenon normal, removidos de 20 porta- \\
dores de pterígios primários e 21, recidivados. A taxa de proliferação foi \\
avaliada em fibroblastos de terceira passagem, quando as culturas foram \\
expostas a agentes antimitóticos: mitomicina Ce 5-fluorouracil. Os dados \\
obtidos foram submetidos à análise estatística. Resultados: Dentre os 41 \\
espécimes cultivados, apenas 1 de pterígio primário e 2 de recidivado \\
proliferaram. Quando expostos a mitomicina C e ao 5-fluorouracil não \\
houve diferença estatisticamente significativa quanto a inibição de \\
proliferação celular. Conclusão: Desta forma, in vitro, ambos os antimi- \\
tóticos estudados têm a mesma eficácia na inibição da proliferação sobre \\
os fibroblastos de cápsulas de Tenon normal. \\
\hline
\end{tabular}

Descritores: Pterígio; Recidiva; Antimitóticos; Mitomicina; Fluoruracila; Fibroblastos/ citologia; Conjuntiva

Trabalho realizado na Faculdade de Medicina da Universidade Estadual Paulista "Júlio Mesquita Filho" UNESP - Botucatu (SP) - Brasil.

${ }^{1}$ Pós-Graduanda do Departamento de Oftalmologia, Otorrinolaringologia e Cirurgia de Cabeça e Pescoço da Faculdade de Medicina da Universidade Estadual Paulista "Júlio Mesquita Filho" - UNESP - Botucatu (SP) - Brasil.

${ }^{2}$ Livre-docente do Departamento de Oftalmologia, Otorrinolaringologia e Cirurgia de Cabeça e Pescoço da UNESP - Botucatu (SP) - Brasil.

${ }^{3}$ Professor do Departamento de Microbiologia do Instituto de Biociências da UNESP - Botucatu (SP) - Brasil. ${ }^{4}$ Professor Titular do Departamento de Bioestatística, Instituto de Biociências da UNESP - Botucatu (SP) Brasil.

Endereço para correspondência: Silvana Artioli Schellini. Faculdade de Medicina da Universidade Estadual Paulista "Júlio Mesquita Filho" - UNESP. Departamento de OFT/ORL/CCP. Distrito Rubião Júnior, s/n Botucatu (SP) CEP 18610-000

E-mail: sartioli@fmb.unesp.br

Recebido para publicação em 06.03.2006

Última versão recebida em 01.07.2006

Aprovação em 27.09.2006

Nota Editorial: Depois de concluída a análise do artigo sob sigilo editorial e com a anuência do Dr. Sérgio Kwitko sobre a divulgação de seu nome como revisor, agradecemos sua participação neste processo.

\section{INTRODUÇ̃̃O}

O pterígio é uma doença altamente prevalente e recorrente em nosso meio, devido à localização geográfica do território brasileiro ${ }^{(1)}$.

Para evitar as recorrências após o seu tratamento cirúrgico, são utilizadas terapias adjuvantes, como a mitomicina $\mathrm{C}(\mathrm{MMC})^{(2-12)}$ e o 5-fluorouracil $(5-\mathrm{FU})^{(13-14)}$.

Fibroblastos provenientes de portadores de pterígios primários e recidivados quando expostos a estes antimitóticos respondem de forma diferente, sendo a MMC mais efetiva inicialmente, tendo ambas a mesma eficácia após três dias da exposição ${ }^{(15)}$. Desta forma, parece haver uma diferença na resposta dos fibroblastos de pterígios ao 5-FU em comparação à MMC.

A grande maioria dos estudos sobre o 5-FU e a MMC, em cultura de células humanas, foi realizada com fibroblastos oriundos de cápsulas de Tenon normais, removidos durante cirurgias filtrantes de glaucoma, de catarata ou de estrabismo ${ }^{(16-18)}$.

Desta forma, o presente estudo foi feito com o objetivo de avaliar o crescimento em cultura de fibroblastos de cápsulas de Tenon normais, provenientes de portadores de pterígios, expostos à MMC e ao 5-FU, a fim de verificar se há uma diferença na resposta proliferativa dos fibroblastos, em decorrência da carga genética dos portadores de pterígio.
\end{abstract}




\section{MÉTODOS}

O protocolo da pesquisa foi aprovado pelo Comitê de Ética e Pesquisa da Faculdade de Medicina de Botucatu (Processo 408/2002), tendo sido incluídos no estudo: indivíduos adultos, portadores de pterígio, que concordaram em participar do estudo. O critério de exclusão foi a presença de pterígio nasal e temporal no mesmo olho, ou qualquer outra patologia ocular associada.

\section{Composição dos grupos e momentos experimentais}

Este foi um estudo prospectivo, aleatorizado, tendo sido utilizados fragmentos de cápsula de Tenon normal, removidos do fundo-de-saco inferior, de 20 portadores de pterígios primários (GPP) e de 21 portadores de pterígios recidivados (GPR). Os fragmentos de tecido foram colocados em meio de cultura e separados conforme provenientes de portadores de pterígio primário ou recidivado.

Os fibroblastos de terceira passagem foram expostos à MMC ou ao 5-FU, tendo sido traçadas curvas de sobrevivência dos fibroblastos, com avaliações realizadas 3, 6, 12 e 18 dias após a exposição às drogas antiproliferativas, através de contagens do número de células com hemocitômetro. Todas as avaliações foram feitas em triplicata.

\section{Método de cultivo celular}

As peças cirúrgicas foram estocadas à temperatura de $5^{\circ} \mathrm{C}$, em período inferior a 3 horas após a exérese, para seu processamento. Sob condições de assepsia, na capela de fluxo laminar, as amostras foram colocadas em placas de Petri de $35 \mathrm{~mm}$ e lavadas com meio DMEM/F12 (Gibco, suplementado com: $5 \mathrm{ml} / \mathrm{l}$ de vitaminas TC minimal Eagle $100 \mathrm{X}, 0,01 \mathrm{U} / \mathrm{ml}$ de insulina, 1,4 g/l de bicarbonato de sódio, $400.000 \mathrm{U} / \mathrm{ml}$ de penicilina, $40 \mathrm{mg} / \mathrm{ml}$ de Gentamicina, 5 mg/ml de Anfotericina-B e 15 mg/l de glutationa, com $\mathrm{pH}$ final de 7,0 ), para a remoção do excesso de células sanguíneas e, então, cortadas em fragmentos de aproximadamente $1 \mathrm{~mm}^{2}$ com pinça e tesoura cirúrgicas delicadas e estéreis. Estes microfragmentos foram colocados em frascos para cultura de células, de $25 \mathrm{~mm}_{2}$ (TPP), com $1 \mathrm{ml}$ de meio DMEM/F12 suplementado com $15 \%$ de soro fetal bovino (SFB Cultilab) e mantidos em estufa a $37^{\circ} \mathrm{C}$ com $5 \%$ de $\mathrm{CO}_{2}$. A adição de meio DMEM/F12 com SFB a $15 \%$ foi feita a cada 3 ou 4 dias, com acompanhamento e exames sob microscópio de imersão, para a observação do comportamento dos fibroblastos (aderência, migração e proliferação) até que se obtivesse um número satisfatório de células em cultura, definido pela observação de células com alta atividade mitótica e semi-confluentes.

\section{Exposição às drogas antimitóticas}

Foram utilizados os fibroblastos da terceira passagem. Após lavagem por três vezes com $1 \mathrm{ml}$ de tripsina, o frasco foi mantido na incubadora a $37^{\circ} \mathrm{C}$, durante 10 minutos, com mais $1 \mathrm{ml}$ de tripsina para que ocorresse o desprendimento celular. Foram acrescentados $3 \mathrm{ml}$ de "phosphate buffered saline" (PBS) e realizada pipetagem em varredura, para se desfazerem os grumos celulares. A tripsina foi, então, inativada com 0,5 ml de SFB. A seguir as células viáveis foram contadas em hemocitômetro e o número de células por $\mathrm{ml}$ calculado segundo a equação:

$$
\frac{\mathrm{n}^{\circ} \text { de células contadas } \mathrm{x} 10^{4}}{\mathrm{n}^{\circ} \text { de quadrados grandes contados }}=\mathrm{n}^{\circ} \text { de células } / \mathrm{ml}
$$

Foram semeadas 5.000 células/poço da placa multiwell 24.

As placas foram colocadas na incubadora por 24 horas para se permitir a aderência celular. Após este período, os fibroblastos foram finalmente expostos aos agentes antimitóticos:

1) Mitomicina $\mathbf{C}$ : após lavagem com $1 \mathrm{ml}$ de $\mathrm{PBS}$, foram colocados $0,5 \mathrm{ml}$ de $\mathrm{MMC}$ a $0,4 \%$ reconstituída com água destilada estéril, durante 3 minutos. Nos poços controles foram colocados $0,5 \mathrm{ml}$ de $\mathrm{PBS}$. Transcorridos estes minutos, foi realizada a lavagem das culturas com $1 \mathrm{ml}$ de PBS, por três vezes. Foram então adicionados $0,5 \mathrm{ml}$ de meio DMEM/12 com $15 \%$ de SFB em cada poço. As culturas foram deixadas novamente na incubadora, sendo adicionados $0,5 \mathrm{ml}$ de meio nutritivo a cada quatro dias.

2) 5-fluorouracil: após lavagem das culturas com $1 \mathrm{ml} \mathrm{de}$ PBS, foi colocado $0,1 \mathrm{ml}$ de $5-\mathrm{FU}$ a $25 \mathrm{mg} / \mathrm{ml}$, em doze poços, num volume de $0,5 \mathrm{ml}$ de DMEM/F12 com $15 \%$ de SFB, portanto as células ficaram expostas a uma concentração de $4,17 \mathrm{mg} / \mathrm{ml}$ de 5-FU. Os quatro poços controles foram deixados sem a adição do 5-FU, sendo apenas adicionados 0,5 ml de DMEM/F12 com $15 \%$ de SFB. As culturas foram levadas novamente à incubadora, sendo acrescentados $0,5 \mathrm{ml}$ de meio nutritivo com $15 \%$ de SFB a cada quatro dias, sem realizar a remoção do mesmo.

\section{Curvas de sobrevivência}

Para a construção das curvas de sobrevivência, os fibroblastos expostos às drogas antimitóticas e os controles foram contados em cada um dos dias previamente estabelecidos, com hemocitômetro.

\section{Análise estatística}

Os dados obtidos quanto à proliferação dos fibroblastos em cultura foram submetidos à análise estatística pelo método de comparações binomiais, aplicando-se o teste de Goodman para situações em que houve necessidade. A significância está apontada na tabela 1 por meio dos valores de P. Na tabela 2, as diferenças significativas estão apresentadas por meio de letras, sendo que duas letras diferentes revelam diferença estatística.

\section{RESULTADOS}

Das 41 linhagens celulares (20 culturas de fibroblastos de cápsulas de Tenon normais de portadores de pterígios primários e 21 de recidivados), somente uma cultura (5\%) de portador de pterígio primário e $3(14,28 \%)$ de pterígio recidivado foram bem sucedidas. Estes foram os espécimes que permitiram o subcultivo até a terceira passagem, utilizados neste 


\begin{tabular}{|c|c|c|c|c|}
\hline \multirow{2}{*}{$\begin{array}{l}\text { Momento de } \\
\text { avaliação }\end{array}$} & \multirow[t]{2}{*}{ Droga } & \multicolumn{2}{|c|}{ Tratamento } & \multirow{2}{*}{$\begin{array}{c}\text { Resultado do teste estatístico } \\
\text { de tratamento }\end{array}$} \\
\hline & & Presente & Ausente & \\
\hline \multirow[t]{2}{*}{$3^{0} \mathrm{dia}$} & 5-fluorouracil & $2500 \pm 2000$ & $12000 \pm 5000$ & $P<0,05$ \\
\hline & Mitomicina C & $1000 \pm 1500$ & $27000 \pm 3000$ & $P<0,05$ \\
\hline \multirow[t]{2}{*}{$6^{\circ} \mathrm{dia}$} & 5-fluorouracil & $1320 \pm 3000$ & $63000 \pm 41000$ & $P<0,05$ \\
\hline & Mitomicina C & $1320 \pm 7000$ & $28000 \pm 33000$ & $P<0,05$ \\
\hline \multirow[t]{2}{*}{$12^{0} \mathrm{dia}$} & 5-fluorouracil & $320 \pm 1000$ & $47000 \pm 23000$ & $P<0,05$ \\
\hline & Mitomicina C & $0 \pm 0$ & $113000 \pm 67000$ & $P<0,05$ \\
\hline \multirow[t]{2}{*}{$18^{0} \mathrm{dia}$} & 5-fluorouracil & $0 \pm 0$ & $11700 \pm 63000$ & $P<0,05$ \\
\hline & Mitomicina C & $0 \pm 0$ & $126000 \pm 81000$ & $P<0,05$ \\
\hline
\end{tabular}

\begin{tabular}{|c|c|c|c|c|}
\hline Droga & $3^{\circ}$ dia & $6^{\circ}$ dia & $12^{\circ} \mathrm{dia}$ & $18^{\circ} \mathrm{dia}$ \\
\hline 5-fluorouracil & $2500 \pm 2000 a A$ & $1320 \pm 3000 \mathrm{aA}$ & $320 \pm 1000 \mathrm{aA}$ & $0 \pm 0 \mathrm{aA}$ \\
\hline Mitomicina C & $1000 \pm 1500 \mathrm{aA}$ & $1320 \pm 7000 \mathrm{aA}$ & $0 \pm 0 \mathrm{aA}$ & $0 \pm 0 \mathrm{aA}$ \\
\hline
\end{tabular}

estudo. Desta forma, as culturas foram utilizadas conjuntamente, sem a comparação entre as culturas provenientes da Tenon normal de pterígios primários ou recidivados.

A tabela 1 apresenta o comportamento proliferativo dos fibroblastos em cultura, sendo que os valores são apresentados em termos da mediana e semi-amplitude, com o resultado da análise estatística, que comparou culturas que receberam o tratamento com droga antimitótica, com os respectivos controles não expostos. No grupo em estudo, o número de células das culturas expostas a ambas as drogas sempre foi menor que os seus controles, em todos os momentos de avaliação $(\mathrm{P}<0,05)$.

A tabela 2 apresenta a proliferação dos fibroblastos em cultura, durante o período em estudo, permitindo comparações entre drogas, nos diversos momentos de observação. As letras minúsculas (vermelhas) comparam as drogas, fixado o momento de observação. Comparando-se as duas drogas, observou-se que as duas drogas inibiram a proliferação dos fibroblastos das cápsulas de Tenon normais igualmente, desde o primeiro até o último dia de contagem. As letras maiúsculas (verdes) revelam o resultado estatístico da comparação entre os momentos de avaliação. As culturas expostas ao 5-FU e a MMC responderam igualmente, não havendo proliferação celular com nenhuma das duas drogas ao longo do tempo.

O detalhamento dos resultados obtidos, assim como as comparações, estão apresentados nos gráficos a seguir.

As contagens do número de fibroblastos não apresentaram diferença estatisticamente significativa quanto à resposta ao 5FU e à MMC, em todos os momentos de avaliação, podendo-se afirmar que houve inibição da proliferação desde o primeiro até o último dia de contagem, com ambas as drogas (Gráfico1).

Já os fibroblastos das culturas controle, não expostas às drogas, proliferaram progressivamente, com contagens celulares maiores que as culturas expostas em todos os momentos de contagem $(\mathrm{P}<0,05)$ (Gráficos 2 e 3$)$.

DISCUSSÃO

Em comparação com estudo prévio ${ }^{(15)}$, com o uso de culturas de fibroblastos de pterígios, observou-se que os fibroblastos provenientes da cápsula de Tenon normal são mais difíceis de serem cultivados, pois apenas 5\% das culturas de cápsulas de Tenon normal de portadores de pterígios primários e apenas $14,28 \%$ das culturas de cápsulas de Tenon normal de pterígios recidivados foram bem sucedidas, enquanto $30 \%$ das culturas provenientes de pterígios primários e $66,66 \%$ das culturas de fibroblastos de pterígios recidivados proliferaram e semi-confluíram, chegando até a terceira passagem ${ }^{(15)}$.

Estudando as diferenças entre fibroblastos de pterígio e de cápsula de Tenon normal em cultura, foi verificado que os primeiros exibiam maior resposta ao soro fetal bovino, necessitando menores concentrações do mesmo para seu cresci-

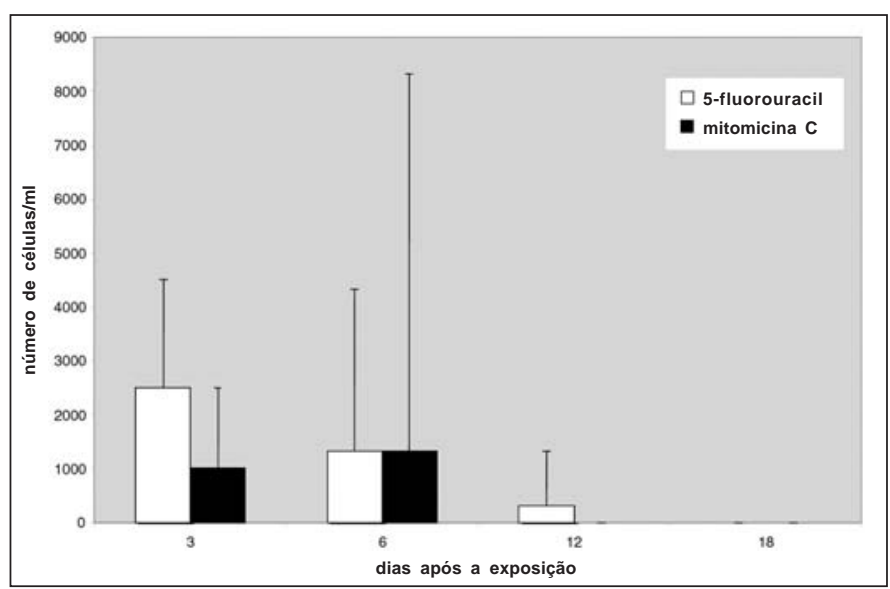

Gráfico 1 - Número de fibroblastos após a exposição ao 5-fluorouracil e à mitomicina $C$ 


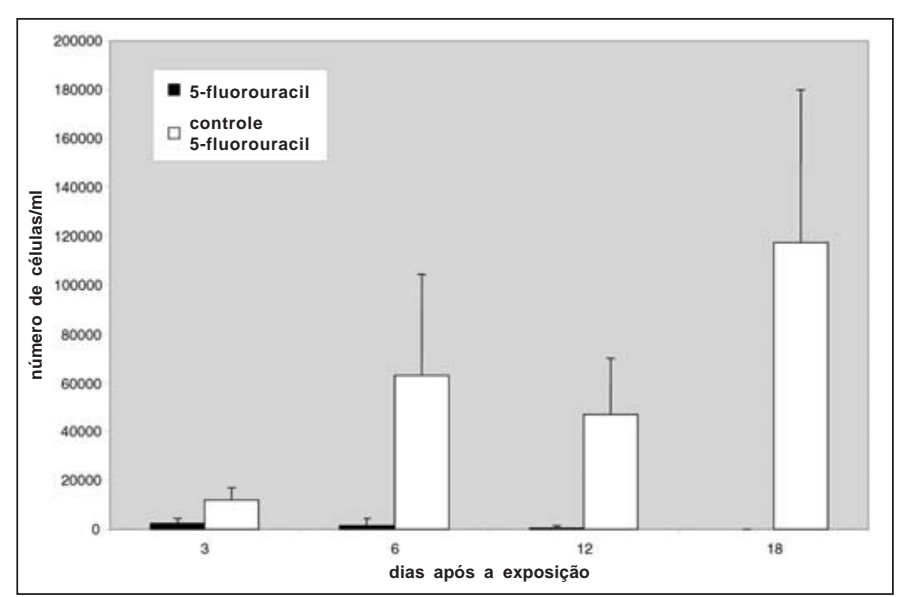

Gráfico 2 - Número de fibroblastos após a exposição ao 5-fluorouracil, com seus respectivos controles

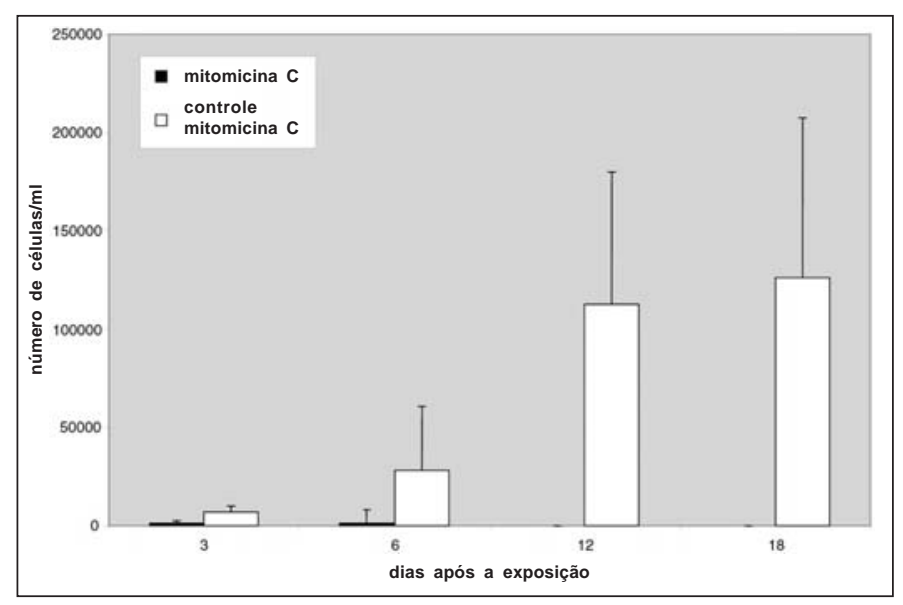

Gráfico 3 - Número de fibroblastos após exposição à mitomicina $\mathrm{C}$, com seus respectivos controles

mento e que proliferam com uma densidade de saturação celular maior, além da independência da adição de fatores de crescimento exógenos $^{(16)}$. Outra observação importante destes mesmos autores foi a de que os fibroblastos da conjuntiva normal foram incapazes de crescer em ágar-gel (mesmo com a adição de fatores de crescimento) e em placas recobertas por colágeno. Apenas os fibroblastos derivados de pterígio foram capazes de formar colônias neste meio semi-sólido, sendo esta a melhor e mais bem aceita correlação in vitro de transformação celular e tumorgenicidade, sugerindo que os fibroblastos de pterígios realmente são células transformadas.

Quanto à exposição aos agentes antiproliferativos, verificou-se que ambas as drogas são efetivas, uma vez que não houve diferença estatística entre o número de fibroblastos presentes nas culturas expostas às drogas e seus respectivos controles não expostos, em todos os momentos de avaliação.

Quanto à comparação entre drogas, foi verificado que, tanto o 5-FU, quanto a MMC são igualmente efetivos na inibição da proliferação dos fibroblastos de cápsulas de
Tenon normais, com ação desde o terceiro dia após a exposição, até o final do período experimental, ocorrido com 18 dias após a exposição.

Existem relatos de inibição da proliferação com o 5-FU já a partir do primeiro dia de exposição com concentração de 1000 $\mu \mathrm{g} / \mathrm{ml}$ e a partir de 3 dias com doses menores ${ }^{(17)}$. Em cultura de fibroblastos de cápsula de Tenon de coelhos, o 5-FU tem efeito similar à MMC na proliferação celular desde o segundo dia após a exposição ${ }^{(19)}$. No presente estudo, a contagem foi feita no terceiro dia, época em que os fibroblastos da cápsula de Tenon normal haviam sido igualmente inibidos pelas duas drogas em estudo.

Porém, uma única exposição dos fibroblastos de cápsulas de Tenon normal, durante 1 ou 5 minutos, nas concentrações de $0,4 \mathrm{mg} / \mathrm{ml}$ para a MMC e $40 \mathrm{mg} / \mathrm{ml}$ para o 5-FU, resulta em inibição parcial do 5-FU contra inibição total da MMC, provavelmente porque o 5-FU é um inibidor da timidilato-sintetase, mais efetivo contra células que estão sintetizando ativamente DNA (fase $\mathrm{S}$ do ciclo celular) ${ }^{(19-20)}$. Como apenas uma fração dos fibroblastos das cápsulas de Tenon normal está sintetizando DNA no momento da exposição, somente estas serão inibidas.

Sabe-se que as células normais possuem maior fragilidade e sensibilidade para o crescimento in vitro, visto que estas culturas têm capacidade proliferativa muito menor que as de pterígios ${ }^{(15-16,21-23)}$. Talvez esta maior sensibilidade dos fibroblastos normais, os deixe mais sensíveis à ação dos antiproliferativos testados no presente estudo.

\section{CONCLUSÃO}

Conclui-se que tanto o 5-FU quanto a MMC foram igualmente efetivos na inibição da proliferação dos fibroblastos provenientes da cápsula de Tenon normal, com início da ação observado já no primeiro dia de contagem (3 dias após a exposição à ambas as drogas).

Desta forma, in vitro, ambos os antimitóticos estudados têm a mesma eficácia na inibição da proliferação sobre os fibroblastos de cápsulas de Tenon normal, quando observados por período acima de 3 e menor que 18 dias após a exposição às drogas.

\section{ABSTRACT}

Purpose: To evaluate the fibroblast proliferation activity of normal Tenon's capsule from primary and recurrent patients with pterygium. Methods: A randomized prospective study was performed with 41 normal Tenon's capsule fragments from 21 primary and 20 recurrent patients with pterygium. The sample was collected from the inferior cul-de-sac. Proliferation rate from fibroblasts were evaluated after mitomycin $\mathrm{C}$ and 5-fluorouracil exposition. Data were submitted to statistical analysis. Results: Of the 41 cultivated normal Tenon's capsules, only 1 from primary and 2 from recurrent pterygium patien- 
ts proliferated. After antimitotic exposition, the proliferation rate was similar with both drugs. Conclusion: Mitomycin and 5-fluorouracil promote similar inhibition regarding proliferation of normal Tenon's fibroblast cultures.

Keywords: Pterygium; Recurrence; Antimitotic agents; Mitomycin; Fluorouracil; Fibroblasts/cytology; Conjunctiva

\section{REFERÊNCIAS}

1. Serracarbassa LL, Dantas MCN. Desordens degenerativas da conjuntiva, córnea e esclera. In: Lima ALH, Nishiwaki- Dantas MC; Alves MR. Doenças externas oculares e córnea. Rio de Janeiro: Cultura Médica; 1999. cap.8, p.371-4. [Manuais básicos CBO].

2. Cardillo JA, Alves MR, José NK, Trajan Neto A, Serpa JF, Ambrósio LE. Uso tópico pós-operatório versus aplicação intra-operatória da mitomicina $\mathrm{C}$ a 0,02 por cento na prevenção de recidivas pós-operatórias do pterígio primário. Arq Bras Oftalmol. 1995;58(6):413-5.

3. Cardillo JA, Kara José N, Alves MR, Poterio MB, Coelho RP, Ambrósio LE. Instilação do colírio de mitomicina $\mathrm{C}$ no pós-operatório do pterígio primário. Arq Bras Oftalmol. 1995;58(2):138-40.

4. Cardillo JA, Alves MR, Kara José N, Camargo JCF, Serpa JF, Ambrósio LE, Moreira Filho DC. Eficácia da mitomicina C a 0,04 por cento na prevenção de recidivas do pterígio primário: aplicação intra-operatória versus uso tópico pós-operatório. Rev Bras Oftalmol. 1996;55(6):15-8.

5. Rubinfeld RS, Stein RM. Topical mitomycin-C for pterygia: is single application appropriate? Ophthalmic Surg Lasers. 1997;28(8):662-9.

6. Alves M, Rosa SF, Gadioli D, Raskin E, Raskin DG, Alves MR. Mitomicina $\mathrm{C}$ subconjuntival como adjuvante no tratamento cirúrgico de pterígio: resultados preliminares. Rev Bras Oftalmol. 2003;62(1):35-40.

7. Avisar R, Gaton DD, Loya N, Appel I, Weinberger D. Intraoperative mitomycin $\mathrm{C} 0.02 \%$ for pterygium: effect of duration of application on recurrence rate. Cornea. 2003;22(2):102-4.

8. Donnenfeld ED, Perry HD, Fromer S, Doshi S, Solomon R, Biser S. Subconjunctival mitomycin $\mathrm{C}$ as adjunctive therapy before pterygium excision. Ophthalmology. 2003;110(5):1012-6.
9. Anduze AL, Burnett JM. Indications for and complications of mitomycin-C in pterygium surgery. Ophthalmic Surg Lasers. 1996;27(8):667-73.

10. Verma N, Garap JA, Maris R, Kerek A. Intraoperative use of mitomycin C in the treatment of recurrent pterygium. P N G Med J. 1998;41(1):37-42.

11. Victoria FHC, Dantas MCN, Almeida PB, Holzchuh N. Efeito da aplicação pré-operatória de mitomicina $\mathrm{C}$ a 0,02 sobre o tratamento de pterígio recidivado. Arq Bras Oftalmol. 1996;59(1):45-8,50.

12. Herzog G, Moreno GL, Arteaga S, Sebastiá R. Colírio de mitomicina C a 0,02 por cento em cirurgias de pterígio primário e pterígio recidivado: indicação estética e funcional. Rev Bras Oftalmol. 2003;62(1):29-33.

13. Schellini SA, Shiratori CN, Spirandelli PH, Shiratori CA, Padovani CR. Uso do 5-fluorouracil no intra-operatório da cirurgia do pterígio. Arq Bras Oftalmol. 2000;63(2):111-4.

14. Shiratori CA, Hoyama E, Schellini LA, Padovani CR. Infiltração de 5fluorouracil no pré-operatório do pterígio. Arq Bras Oftalmol. 2003;66(4): 499-503.

15. Viveiros MMH, Schellini SA, Rogatto SR, Rainho C, Padovani CR. Análise do cultivo de fibroblastos da cápsula de Tenon de pterígios primários e recidivados. Arq Bras Oftalmol. 2004;67(4 Supl):37.

16. Chen JK, Tsai RJ, Lin SS. Fibroblasts isolated from human pterygia exhibit transformed cell characteristics. In Vitro Cell Dev Biol. 1994;30A(4):243-8.

17. Khaw PT, Sherwood MB, MacKay SL, Rossi MJ, Schultz G. Five-minute treatments with fluorouracil, floxuridine, and mitomycin have long-term effects on human Tenon's capsule fibroblasts. Arch Ophthalmol. 1992;110(8): 1150-4.

18. Madhavan HN, Rao SB, Vijaya L, Neelakantan A. In vitro sensitivity of human Tenon's capsule fibroblasts to mitomycin C and its correlation with outcome of glaucoma filtration surgery. Ophthalmic Surg. 1995;26(1):61-7.

19. Yamamoto T, Varani J, Soong HK, Lichter PR. Effects of 5-fluorouracil and mitomycin $\mathrm{C}$ on cultured rabbit conjunctival fibroblasts. Ophthalmology. 1990;97(9):1204-10.

20. Jampel HD. Effect of brief exposure to mitomycin C on viability and proliferation of cultured human Tenon's capsule fibroblasts. Ophthalmology. 1992;99(9):1471-6.

21. Levy WJ, Levy J, Clapper WE. Pterygium tissue culture histoimmunological study. Arch Ophthalmol. 1970;83(4):402-5.

22. Kria L, Ohira A, Amemiya T. Growth factors in cultured pterygium fibroblasts: immunohistochemical and ELISA analysis. Graefes Arch Clin Exp Ophthalmol. 1998;236(9):702-8.

23. Baldó DBM, Arvelo F, Acevedo M. Estudio biomorfológico en cultivo de fibroblastos obtenidos de pterigión primario y pterigión recidivante tratados con mitomicina C. Rev Oftalmol Venez. 1998; 54(3):28-42. 